\title{
Validation of heavy water cross section using AmBe neutron source
}

\author{
Michal Kostal ${ }^{1, *}$, Martin Schulc ${ }^{1, * *}$, Evzen Novak $^{1}$, Tomas Czakoj $^{1}$, Zdenek Matej $^{2}$, Frantisek Cvachovec $^{3}$, Filip $_{\text {Mravec }}^{2}$, \\ Bohumil Jansky ${ }^{1}$, and Luiz Leal ${ }^{4}$ \\ ${ }^{1}$ Research Centre Rez, Hlavni 130, Husinec-Rez, Czech Republic \\ ${ }^{2}$ Masaryk University, Botanická 15, Brno 612 00, Czech Republic \\ ${ }^{3}$ University of Defence, Kounicova 65, Brno 612 00, Czech Republic \\ ${ }^{4}$ Institut de Radioprotection et de Sureté Nucléaire, 31 Avenure de la Division le Clerc, 92262 Fonenay-aux-Roses, France
}

\begin{abstract}
Physical quantities derived from integral experiments can usually be measured much more accurately than that from differential nuclear data. The accurate knowledge of integral parameters provide excellent grounds for testing and tuning differential data such as, for instance, cross sections. Measurement of neutron leakage spectra with ${ }^{252} \mathrm{Cf}$ neutron source located at sphere center is often used for integral experiments. While this type of experiments provide information for cross section tuning, however, care must be taken to avoid misleading interpretation, namely, at high energies due to the very low portion of high energy neutrons in ${ }^{252} \mathrm{Cf}$ spectrum. This issue can be alleviated by the use of point source with different spectra shape. For that purpose one suitable candidate seems to be the AmBe neutron source which has a relatively high average energy and peak character of emitted neutrons. Indeed, AmBe seems an interesting option because the calculated leakage neutron spectra are not very sensitive to the input shape of the neutron spectra. Thus the neutron leakage spectra calculated using tabulated of International Organization for Standardization spectra is nearly the same as stilbene measured AmBe spectra as an input.
\end{abstract}

\section{Introduction}

The correct description of neutron transport in oxygen is an essential task for correct reactor dosimetry transport models, because oxygen is an essential part of important reactor materials like water and concrete. The simple spherical benchmark of diameter $50 \mathrm{~cm}$ filled by $\mathrm{D}_{2} \mathrm{O}$ was chosen for validation experiment, with a point $\mathrm{AmBe}$ source was placed in its center. Past experiments were performed using the same $\mathrm{D}_{2} \mathrm{O}$ sphere and ${ }^{252} \mathrm{Cf}$ source. This set of experiments are carried with the intent of testing and improving cross section libraries for the purposes of deep penetration issues. Fast neutron leakage spectra were measured in the distance of $100 \mathrm{~cm}$ from the center of the benchmark sphere. The measurement was carried out with a stilbene scintillation detector in the energy range of 1-10 $\mathrm{MeV}$. Due to a peak character of AmBe spectra, the detector arrangement was successfully tested in LVR-15 light water reactor silicon filtered field [1].

\section{Experimental and calculation methods}

\subsection{Neutron source}

The AmBe neutron spectra is not standard, because the energy distribution of neutrons formed in the nuclear reaction on $\mathrm{Be}$, namely ${ }^{9} \mathrm{Be}+{ }^{4} \mathrm{He}->{ }^{12} \mathrm{C}^{*}+\mathrm{n}$, is driven by the energy of the interacting alpha particle. The alpha particles have very low penetrating properties and can be strongly attenuated even by air. Thus the energy distribution of leaking neutrons highly depend on the distance between the place of creation of the alpha particle and the $\mathrm{Be}$ atom - which is highly affected by grain size of both Be and $\mathrm{AmO}_{2}$ and its porosity. Due to this fact the characterization of AmBe was performed by means of scintillation spectrometry, see Table1. It is worth noting that the measured neutron spectra is very close to the standard ISO as shown in Figure 1.

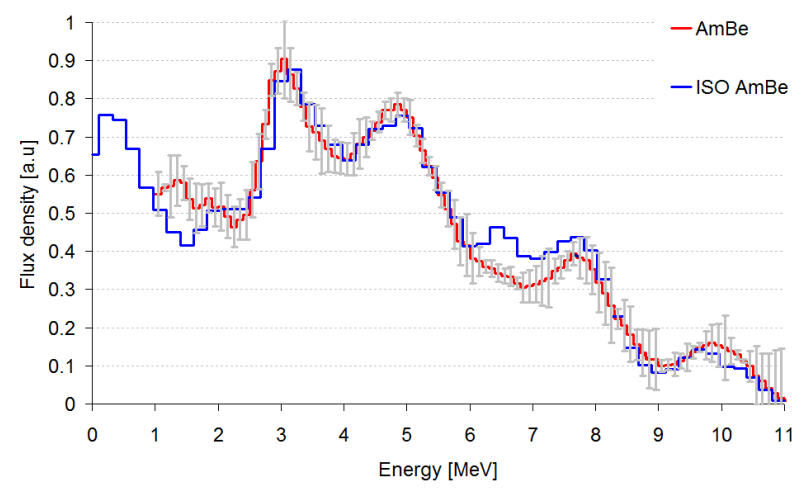

Figure 1. Measured AmBe spectra compared with tabulated values.

\footnotetext{
*e-mail: michal.kostal@cvrez.cz

**e-mail: martin.schulc@cvrez.cz
} 
The validation of the cross section is realized by means of comparison between leakage neutron flux measured and calculated one using the tested cross sections. The measured AmBe neutron spectra was used for source description. However, it is worth noting, the calculated neutron spectra after passing of $50 \mathrm{~cm}$ of heavy water sphere using ISO or measured spectra are nearly the same. The comparison between calculation using measured AmBe spectra or ISO spectra is plotted in the Figure 2. This result is very important, because it minimizes the significant source of uncertainties.

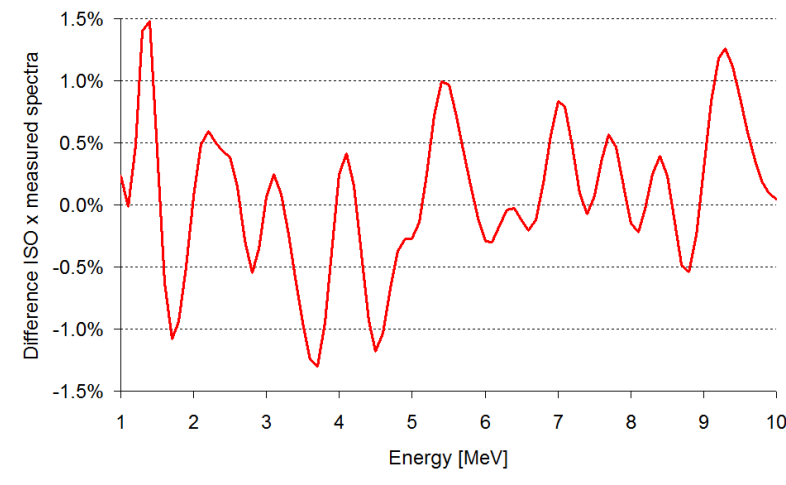

Figure 2. Comparison between leakage spectra calculated with ISO AmBe spectra and measured spectra.

\subsection{Experimental set up}

Neutron spectra in the 1 to $10 \mathrm{MeV}$ energy range were measured via the proton-recoil method using a cylindrical stilbene scintillator (with dimensions of $10 \mathrm{~mm} \times 10 \mathrm{~mm}$ ) with neutron and gamma pulse shape discrimination (hereinafter stilbene). The two-parameter spectrometric system [2] is fully digitized and able to process up to 300000 impulses per second. Two fast ADCs working at a 500 MS/s sampling frequency are used and the digital signal processing is implemented into a field-programmable gate array (FPGA), details can be found in [3]. The calibration of the detector was tested on Si filtered beam, which ensures high reliability of measured neutron spectra. The background neutron spectrum was subtracted using special shielding cones [4].

\subsection{Calculation methods}

Calculations were performed using the MCNP6 Monte Carlo code [5] with the ENDF/B-VII.1 [6], ENDF/B-VIII [7] JENDL-4.0 [8] nuclear data libraries and IRSN evaluation of oxygen which were processed using NJOY code [9]. The calculated spectrum was broadened with respect to the stilbene resolution; see [1].

\section{Results}

The calculated neutron leakage spectra are compared with an experiment in Figure 3. It can be noted that the agreement is relatively good in the peak areas, whereas in lower energy regions it worsens. Significant differences among libraries can be observed. Namely, there is a significant JENDL-4 overprediction regarding to ENDF/B-VIII, which is the closest to the experimental results.

Table 1. Measured AmBe neutron leakage spectra.

\begin{tabular}{|c|c|c|c|c|c|}
\hline $\mathrm{E}_{u p}$ & $\mathrm{~d} \Phi$ & Unc. & $\mathrm{E}_{u p}$ & $\mathrm{~d} \Phi$ & Unc. \\
\hline$[\mathrm{MeV}]$ & [a.u.] & {$[\%]$} & {$[\mathrm{MeV}]$} & [a.u.] & [\%] \\
\hline 1.0 & $6.299 \mathrm{E}-1$ & 5.4 & 6.1 & $3.816 \mathrm{E}-1$ & 7.2 \\
\hline 1.1 & $5.504 \mathrm{E}-1$ & 6.5 & 6.2 & $3.735 \mathrm{E}-1$ & 4.9 \\
\hline 1.2 & $5.669 \mathrm{E}-1$ & 3.1 & 6.3 & $3.598 \mathrm{E}-1$ & 3.4 \\
\hline 1.3 & $5.705 \mathrm{E}-1$ & 8.7 & 6.4 & $3.548 \mathrm{E}-1$ & 3.7 \\
\hline 1.4 & $5.858 \mathrm{E}-1$ & 7.3 & 6.5 & $3.425 \mathrm{E}-1$ & 3.8 \\
\hline 1.5 & $5.792 \mathrm{E}-1$ & 5.3 & 6.6 & $3.348 \mathrm{E}-1$ & 3.6 \\
\hline 1.6 & $5.370 \mathrm{E}-1$ & 6.2 & 6.7 & $3.344 \mathrm{E}-1$ & 3.9 \\
\hline 1.7 & $5.126 \mathrm{E}-1$ & 7.2 & 6.8 & $3.155 \mathrm{E}-1$ & 3.4 \\
\hline 1.8 & $5.208 \mathrm{E}-1$ & 6.3 & 6.9 & $3.056 \mathrm{E}-1$ & 4.9 \\
\hline 1.9 & $5.400 \mathrm{E}-1$ & 4.9 & 7.0 & $3.093 \mathrm{E}-1$ & 5.2 \\
\hline 2.0 & $5.145 \mathrm{E}-1$ & 5.8 & 7.1 & $3.135 \mathrm{E}-1$ & 5.6 \\
\hline 2.1 & $5.183 \mathrm{E}-1$ & 6.9 & 7.2 & $3.227 \mathrm{E}-1$ & 7.2 \\
\hline 2.2 & $4.915 \mathrm{E}-1$ & 6.4 & 7.3 & $3.300 \mathrm{E}-1$ & 8.2 \\
\hline 2.3 & $4.640 \mathrm{E}-1$ & 6.1 & 7.4 & $3.477 \mathrm{E}-1$ & 4.4 \\
\hline 2.4 & $4.833 \mathrm{E}-1$ & 6.1 & 7.5 & $3.577 \mathrm{E}-1$ & 4.2 \\
\hline 2.5 & $4.955 \mathrm{E}-1$ & 7.1 & 7.6 & $3.766 \mathrm{E}-1$ & 3.9 \\
\hline 2.6 & $5.615 \mathrm{E}-1$ & 7.9 & 7.7 & $3.942 \mathrm{E}-1$ & 4.3 \\
\hline 2.7 & $6.358 \mathrm{E}-1$ & 7.8 & 7.8 & $3.820 \mathrm{E}-1$ & 6.1 \\
\hline 2.8 & $7.335 \mathrm{E}-1$ & 4.8 & 7.9 & $3.760 \mathrm{E}-1$ & 6.8 \\
\hline 2.9 & $8.493 \mathrm{E}-1$ & 5.2 & 8.0 & $3.523 \mathrm{E}-1$ & 7.1 \\
\hline 3.0 & $8.733 \mathrm{E}-1$ & 6.7 & 8.1 & $3.187 \mathrm{E}-1$ & 8.3 \\
\hline 3.1 & $9.044 \mathrm{E}-1$ & 10.7 & 8.2 & $2.895 \mathrm{E}-1$ & 8.8 \\
\hline 3.2 & $8.627 \mathrm{E}-1$ & 7.6 & 8.3 & $2.581 \mathrm{E}-1$ & 10.3 \\
\hline 3.3 & $8.267 \mathrm{E}-1$ & 5.2 & 8.4 & $2.227 \mathrm{E}-1$ & 4.0 \\
\hline 3.4 & $7.792 \mathrm{E}-1$ & 4.7 & 8.5 & $2.059 \mathrm{E}-1$ & 7.4 \\
\hline 3.5 & $7.269 \mathrm{E}-1$ & 7.1 & 8.6 & $1.821 \mathrm{E}-1$ & 7.8 \\
\hline 3.6 & $7.123 \mathrm{E}-1$ & 7.7 & 8.7 & $1.551 \mathrm{E}-1$ & 5.0 \\
\hline 3.7 & $6.895 \mathrm{E}-1$ & 9.0 & 8.8 & $1.336 \mathrm{E}-1$ & 6.8 \\
\hline 3.8 & $6.688 \mathrm{E}-1$ & 6.8 & 8.9 & $1.171 \mathrm{E}-1$ & 8.2 \\
\hline 3.9 & $6.498 \mathrm{E}-1$ & 5.2 & 9.0 & $1.162 \mathrm{E}-1$ & 8.6 \\
\hline 4.0 & $6.452 \mathrm{E}-1$ & 5.1 & 9.1 & $1.002 \mathrm{E}-1$ & 3.4 \\
\hline 4.1 & $6.417 \mathrm{E}-1$ & 5.2 & 9.2 & $1.023 \mathrm{E}-1$ & 3.3 \\
\hline 4.2 & $6.550 \mathrm{E}-1$ & 6.2 & 9.3 & $1.039 \mathrm{E}-1$ & 4.3 \\
\hline 4.3 & $6.823 \mathrm{E}-1$ & 7.2 & 9.4 & $1.116 \mathrm{E}-1$ & 3.6 \\
\hline 4.4 & $6.989 \mathrm{E}-1$ & 6.0 & 9.5 & $1.226 \mathrm{E}-1$ & 4.6 \\
\hline 4.5 & $7.162 \mathrm{E}-1$ & 3.8 & 9.6 & $1.354 \mathrm{E}-1$ & 3.4 \\
\hline 4.6 & $7.383 \mathrm{E}-1$ & 4.0 & 9.7 & $1.482 \mathrm{E}-1$ & 3.2 \\
\hline 4.7 & $7.702 \mathrm{E}-1$ & 3.8 & 9.8 & $1.532 \mathrm{E}-1$ & 4.7 \\
\hline 4.8 & $7.708 \mathrm{E}-1$ & 4.3 & 9.9 & $1.592 \mathrm{E}-1$ & 5.7 \\
\hline 4.9 & $7.850 \mathrm{E}-1$ & 4.3 & 10.0 & $1.536 \mathrm{E}-1$ & 6.3 \\
\hline 5.0 & 7.703E-1 & 4.2 & 10.1 & $1.465 \mathrm{E}-1$ & 9.0 \\
\hline 5.1 & $7.514 \mathrm{E}-1$ & 5.4 & 10.2 & $1.390 \mathrm{E}-1$ & 4.6 \\
\hline 5.2 & $7.044 \mathrm{E}-1$ & 4.1 & 10.3 & $1.294 \mathrm{E}-1$ & 3.2 \\
\hline 5.3 & $6.642 \mathrm{E}-1$ & 4.3 & 10.4 & $1.120 \mathrm{E}-1$ & 3.0 \\
\hline 5.4 & $6.236 \mathrm{E}-1$ & 3.8 & 10.5 & $9.885 \mathrm{E}-2$ & 5.0 \\
\hline 5.5 & $5.925 \mathrm{E}-1$ & 4.3 & 10.6 & $7.459 \mathrm{E}-2$ & 8.3 \\
\hline 5.6 & $5.480 \mathrm{E}-1$ & 4.5 & 10.7 & $6.000 \mathrm{E}-2$ & 7.8 \\
\hline 5.7 & $5.116 \mathrm{E}-1$ & 5.5 & 10.8 & $4.132 \mathrm{E}-2$ & 9.5 \\
\hline 5.8 & $4.711 \mathrm{E}-1$ & 7.1 & 10.9 & $2.745 \mathrm{E}-2$ & 11.7 \\
\hline 5.9 & $4.267 \mathrm{E}-1$ & 7.0 & 11.0 & $1.604 \mathrm{E}-2$ & 13.1 \\
\hline 6.0 & 4.164E-1 & 8.7 & 11.1 & $9.644 \mathrm{E}-3$ & 14.0 \\
\hline
\end{tabular}


This kind of discrepancies seems to be rather effect of angularities than impreciseness in elastic/inelastic cross section because most significant variations are in region 5-9 MeV where effect of elastic/nonelastic is not so large, see [10] but JENDL-4 and ENDF/B-VII.1 differ significantly in forward scattering [11]. It is worth noting that in the case of experiment involving Cf source placed in the center of sphere, which was realized in an additional experiment [10], the agrement was better than in case of $\mathrm{AmBe}$ (see Figure 5). This might be connected with higher average neutron energy (see Table 2).

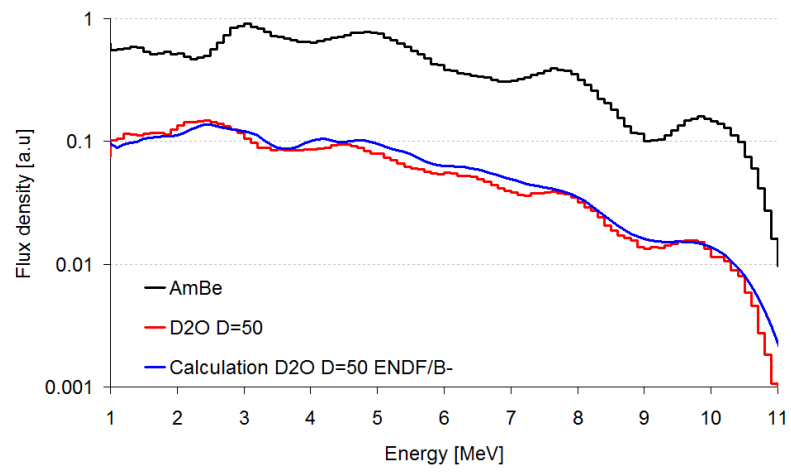

Figure 3. Comparison of calculated and measured leakage flux from heavy water sphere of diameter $50 \mathrm{~cm}$ with measured AmBe leakage spectra.

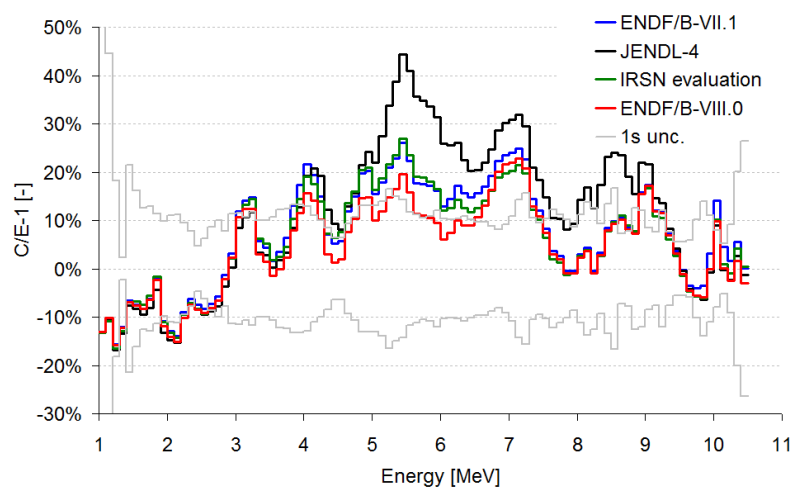

Figure 4. C/E-1 for various libraries determined leakage flux of $\mathrm{AmBe}$ source in a heavy water sphere of diameter $50 \mathrm{~cm}$.

Table 2. Share of fast neutrons.

\begin{tabular}{lll}
\hline Energy & $\mathrm{AmBe}$ & ${ }^{252} \mathrm{Cf}$ \\
\hline$>7 \mathrm{MeV}$ & $17.8 \%$ & $1.3 \%$ \\
$>8 \mathrm{MeV}$ & $9.6 \%$ & $0.6 \%$ \\
$>9 \mathrm{MeV}$ & $5.0 \%$ & $0.3 \%$ \\
\hline
\end{tabular}

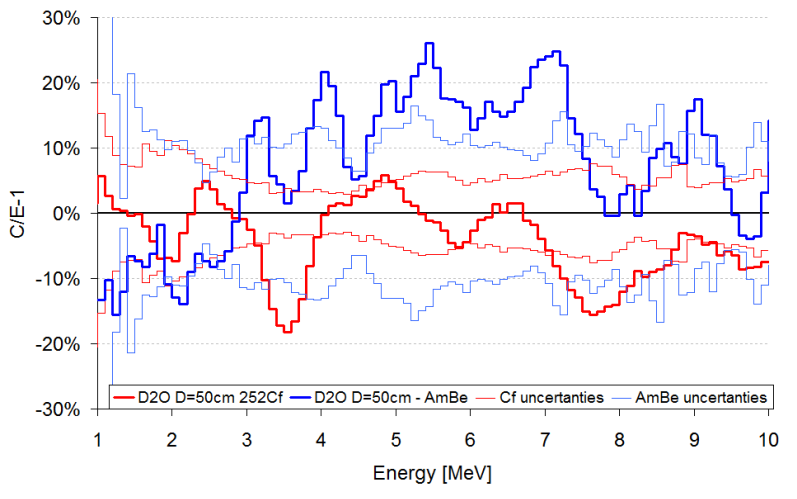

Figure 5. C/E-1 for ENDF/B-VII.1 for and AmBe leakage flux. $\mathrm{C} / \mathrm{E}-1$ of leakage flux of ${ }^{252} \mathrm{Cf}$ and $\mathrm{AmBe}$ sources in $\mathrm{D}_{2} \mathrm{O}$ sphere of diameter $50 \mathrm{~cm}$ (calculation in ENDF/B-VII.1).

\section{Conclusions}

The leakage beam of AmBe source in $\mathrm{D}_{2} \mathrm{O}$ sphere was measured and compared with experiment. The results imply that in the description of neutron transport through $\mathrm{D}_{2} \mathrm{O}$, there exist issues, most probably in connection with the ${ }^{16} \mathrm{O}$ angular distribution. This experiment is in agreement with previous experiments realized in VVER-1000 mock-up where JENDL-4 in concrete shows also significant over prediction. Transmission experiments with $\mathrm{AmBe}$ in the center of the sphere seems to be an interesting validation tool, however there are few limitations. The most important are connected with uncertainty, because AmBe is not standard with low uncertainties. Other disadvantage is the sample size, since the ${ }^{252} \mathrm{Cf}$ is small. However it has also advantages. The AmBe has much higher average energy, thus seems to be an interesting supplement of the ${ }^{252} \mathrm{Cf}$ experiments, due to peak character it is also interesting source for testing of stilbene energy calibration. Advantage is also long decay time against ${ }^{252} \mathrm{Cf}$ source.

\section{Acknowledgments}

Presented results were obtained with the use of infrastructure Reactors LVR-15 and LR-0, which is financially supported by the Ministry of Education, Youth and Sports project LM2015074 and also financially supported by the Ministry of Education, Youth and Sports Czech Republic - project LQ1603 Research for SUSEN. This work has been realized within the SUSEN Project (established in the framework of the European Regional Development Fund (ERDF) in project CZ.1.05/2.1.00/03.0108 and of the European Structural Funds and Investment Funds (ESIF) in the project CZ.02.1.01/0.0/0.0/15_008/0000293), which is financially supported by the Ministry of Education, Youth and Sports - project LM2015093 Infrastructure SUSEN.

\section{References}

[1] Kostal, M. et al., Applied Radiation and Isotopes 128,41-48 (2017) 
[2] Veskrna, M. et al., 18th Topical Meeting of the Radiation Protection and Shielding Division of ANS, Knoxville, TN USA, 2014, (2014)

[3] Matej, Z. et al., LAP LAMBERT Academic publishing, 136 (2014) ISBN 978-3-659-59970-5

[4] Schulc, M. et al., Nuclear Instruments and Methods in Physics Research Section A 914,53-56 (2019)

[5] Goorley, T. et al., Nuclear Technology 180,298-315 (2012)

[6] Chadwick, M. B. et al., Nuclear Data Sheets 112, 2887-2996 (2011)
[7] Brown,D. A. et al., Nuclear Data Sheets, 148, 1-142 (2018)

[8] Shibata, K. et al., J. Nucl. Sci. Technol. 48,1-30 (2011)

[9] MacFarlane, R.E., et al., Nuclear Data Sheets 111,2739-2890 (2010)

[10] Schulc, M. et al., Applied Radiation and Isotopes 133,45-50 (2018)

[11] Kostal, M. et al., Annals of Nuclear Energy 94,672683 (2016) 